\title{
How to restore medical services in the ophthalmic department in the post-pandemic period of COVID-19
}

\author{
Jiao Xia ${ }^{1}$, Rongli Wang ${ }^{1}$, Min Tian ${ }^{2}$, Xunlian $W_{u^{1}}$ \\ ${ }^{1}$ Department of Infection Management, The Affiliated Hospital of Southwest Medical University, Luzhou, China; ${ }^{2}$ Department of ophthalmology, \\ The Affiliated Hospital of Southwest Medical University, Luzhou, China \\ Contributions: (I) Conception and design: J Xia, X Wu; (II) Administrative support: R Wang; (III) Provision of study materials or patients: M Tian; (IV) \\ Collection and assembly of data: J Xia; (V) Data analysis and interpretation: J Xia, X Wu; (VI) Manuscript writing: All authors; (VII) Final approval \\ of manuscript: All authors. \\ Correspondence to: Xunlian Wu. Department of Infection Management, The Affiliated Hospital of Southwest Medical University, 25\# Taiping Road, \\ Jiangyang District, Luzhou, China. Email: 794177985@qq.com.
}

\begin{abstract}
Currently, the epidemics situation of COVID-19 is still grim. As a high-risk department, it is necessary to take corresponding prevention and control measures in the ophthalmology department. To guide the ophthalmology department of medical institutions to recover from the post-pandemic period of COVID-19, we designed relevant prevention and control strategies formulated by the National Health Committee, combined with our practical work of hospital pandemic management. The prevention and control strategies contained ward settings, channel design, allocation of protective equipment, screening of hospitalized patients, supervision-guided improvement, ward disinfection, the management of patients and escorts. There are 64 doctors and nurses who had standardized training during the post-pandemic period in the ophthalmology department. A total of 185 patients were admitted to the ophthalmology department of our institution, and 107 operations were successfully performed during that period. We made a follow-up visit two weeks after discharge to ask whether the patients had fever and/or other symptoms and whether he had been diagnosed with a COVID-19 case. Ultimately the ophthalmic ward was free of infection with the novel coronavirus. These showed that our prevention strategies were effective for ophthalmology department to defending COVID-19 in the process of recovering medical services.
\end{abstract}

Keywords: Novel coronavirus pneumonia (NCP); ophthalmology department; recovery of medical service; prevention and control strategies

Submitted Oct 16, 2020. Accepted for publication Feb 03, 2021.

doi: 10.21037/apm-20-2424

View this article at: http://dx.doi.org/10.21037/apm-20-2424

Novel coronavirus pneumonia (NCP), which has been named as COVID-19 by the World Health Organization is still grim (1). Until to April 13, 2020, a cumulative total of 83,597 confirmed cases and 2,101 daily confirmed cases had been reported in China. More than 1.7 million cases had been confirmed globally. Although the level of emergency response to the COVID-19 epidemic was adjusted from the first level of public health emergencies to the second level in our province since February 26, 2020, we should still remain alert to the potential risk of disease onset. The risk of COVID-19 transmission between doctors and patients was high in ophthalmology wards because it is often necessary for medical staff to closely observe the eye conditions of patients for the diagnosis and treatment of ophthalmic diseases (2). In the early days of the COVID-19 outbreak, several ophthalmologists were infected with COVID-19 (3). It was investigated the eye symptoms of 26 ophthalmologists who were diagnosed with COVID-19 in Wuhan from February 26 to March 20, 2020, and most of them (11 cases, $42.3 \%$ ) in the case group had eye symptoms (4).

Transmission risk is still high as some asymptomatic patients often emerged (5). Therefore, it is significant 
to explore effective prevention and control strategies to guide the work of ophthalmology in the post-pandemic era, which can also improve the access of patients to health services and the prevention of other infectious diseases. For the ophthalmology department, it is important to protect the safety of patients and medical staff while ensuring disease prevention and control during the recovery of the medical service. According to the relevant prevention and control programs (6-8) formulated by the National Health Committee, in combination with the practice of our institution, we designed relevant strategies to guide ophthalmologists to resume clinical work in the postpandemic era. The prevention and control experiences reported in the current study were shown to be effective. Dennis' article focuses on the principles of ophthalmology in coping with COVID-19, however our experience is more suitable for practical work which is more convenient for ophthalmologists to use (9).

\section{Pre-hospital and outpatient education}

We delivered some popular science articles through the official WeChat of our hospital, which enabled the patients to determine whether they needed emergency treatment or not. For the patients who had open eye trauma, sudden eye distension, eye pain, vision decline or visual occlusion, we firmly suggested them to visit the hospital with protection in time. On the other hand, for the patients opted for treatment, a delayed visit was recommended. At a prominent position of the ophthalmology section in the outpatient department, advertising about COVID-19 prevention was presented. All the medical staff in the ophthalmology department carried out related online studies and trainings regularly.

\section{Prevention and control strategies in the ophthalmology ward}

\section{Admission screening}

Patients with ophthalmic disorders went through a 3-level process before admission (10), as shown in Figure 1. Single entry and single exit were implemented for inpatient buildings. To enter into the inpatient building, the patients had to present the inpatient wristband, and the escorts had to possess both an identity card and a companion card. The medical staff entered into the inpatient building by work certificate, then were able to go to the ophthalmology department. Equipment for automatic temperature measurements was set at the entrance of each inpatient building. Anyone whose body temperature was higher than $37.3{ }^{\circ} \mathrm{C}$ was given a disposable medical surgical mask by the security and brought to the fever clinic for further examination. Each inpatient building was equipped with a dedicated elevator for patients with a fever, which was wiped and disinfected with $1,000 \mathrm{mg} / \mathrm{L}$ chlorine-containing disinfectant every 2 hours. An epidemiological investigation counter was set at the entrance of the ward, which was a wellventilated place in the ophthalmology department. After the patients and escorts entered into the ward, they presented the primary screening questionnaire of patients and escorts (as shown in Figure 2). On April 13, the hospital adjusted the screening questionnaire according to the needs of the global epidemic, as shown in Figure 3, or the electronic health code, then patients and companions could enter the ward. As of April 17, 46 patients with a fever were detected in the ophthalmic ward, all of whom were brought to the fever clinic for treatment. A total of 14 patients underwent testing for COVID-19 with throat swabs, all of which were negative. Emergency patients for whom COVID-19 could not be ruled out were transferred to an isolated observation room for preliminary ophthalmic treatment. Only after the nucleic acid test was negative twice could the patients be transferred to the ophthalmology department after consultation with the chief resident.

\section{Allocation of protective equipment}

In the face of sudden outbreak, the supply and demand of hospital protective equipment was tight. Graded protection was applied according to the risk of possible exposure to infected patients, and different protective equipment was selected and worn to obtain a reasonable protective effect. All staff, including the physician-in-charge, residents, trainees, continuing doctors, and even employed cleaners, used the protective equipment equally. The Department will issue appropriate masks according to the risk of different operations. Private use of protective equipment was strictly prohibited. A daily inventory and usage was recorded and updated in order to have a clear understanding about the reserves of protective equipment (11).

\section{Supervision-guided improvement}

During the recovery period of the medical service, the hospital authorities set up a supervision team composed of 


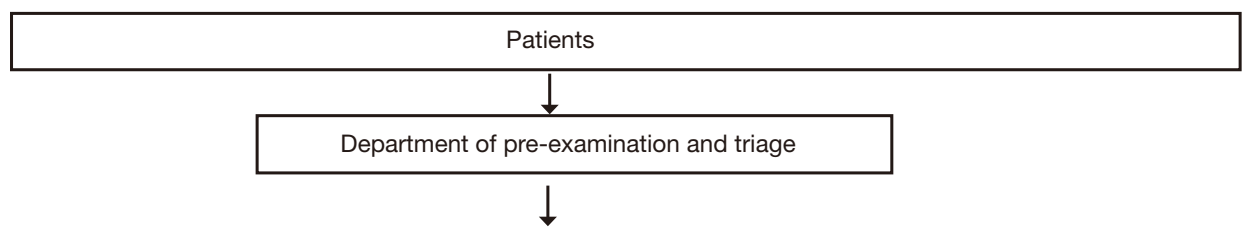

Body temperature measurement, filling in the Primary screening questionnaire of patients and companions (as shown in Figures 2 and 3), instructing patients to wear the mask correctly
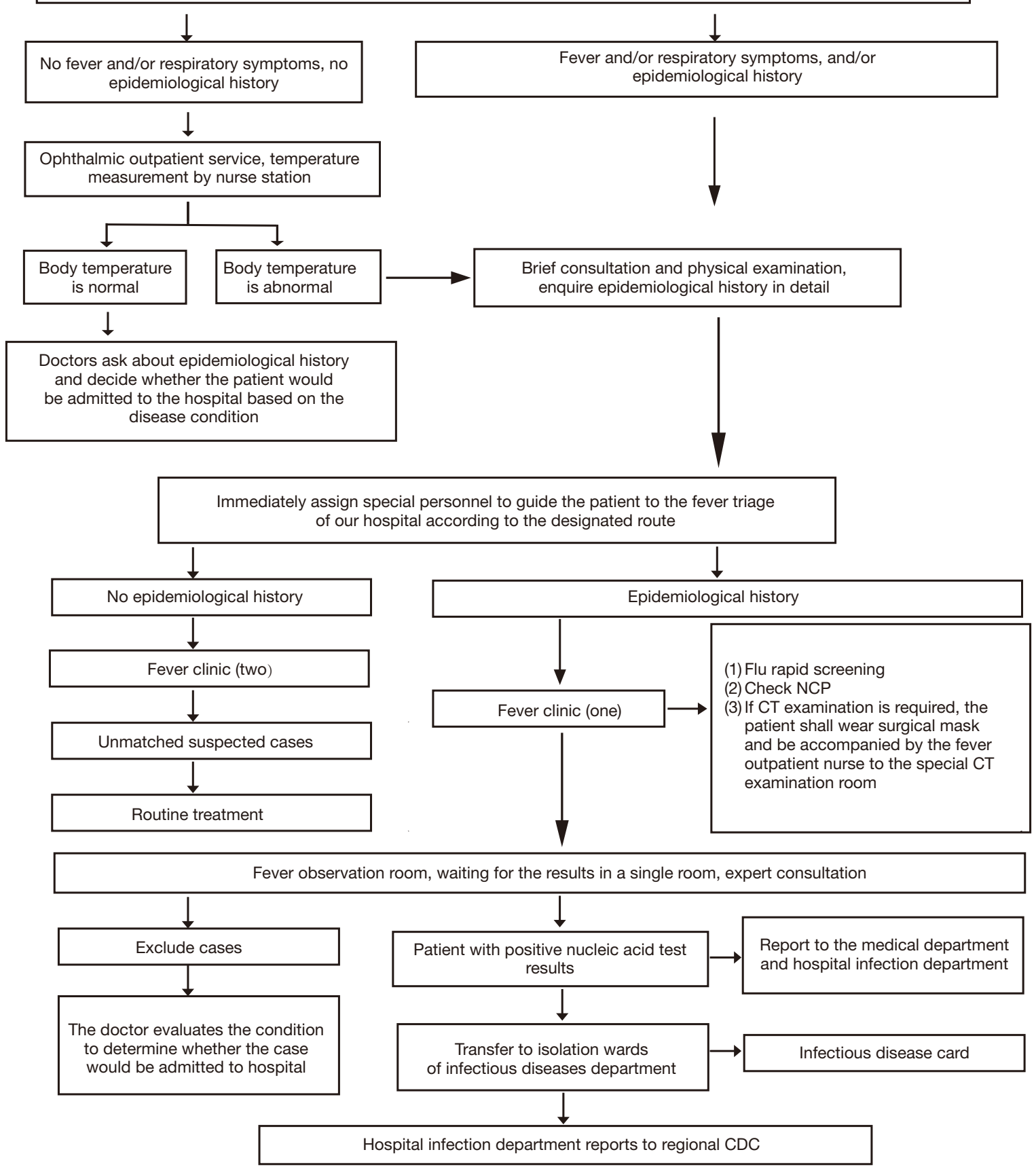

Figure 1 Screening procedures for hospitalized patients in ophthalmology department. 
Name:

ID:
Telephone:

Address:

\section{Epidemiological history}

(1) Travel or residence history in and around high-risk areas of the epidemic or other communities with reported cases within 14 days prior to onset

$$
\text { Yes } \square \quad \text { No } \square
$$

(2) A history of exposure to novel coronavirus infection (nucleic acid positive) within 14 days prior to onset

$$
\text { Yes } \square \quad \text { No } \square
$$

(3) In the 14 days prior to onset of illness, the patient had been exposed to fever or respiratory symptoms from high-risk areas of the epidemic and surrounding areas, or from communities where cases were reported

$$
\text { Yes } \square \quad \text { No } \square
$$

(4) Cluster disease (2 or more cases of fever and/or respiratory symptoms in a small area such as family, office, school class, etc. within 2 weeks)

$$
\text { Yes } \square \quad \text { No } \square
$$

2 Clinical manifestation

(1) Fever and/or respiratory symptoms:

$\begin{array}{lll}\text { (2) It has imaging features of COVID-19: } & \text { Yes } \square \quad \text { No } \square \\ & \text { Yes } \square \quad \text { No } \square\end{array}$

(3) The total number of white blood cells was normal or decreased, Lymphocyte counts are normal or reduced:

$$
\text { Yes } \square \quad \text { No } \square
$$

\section{Patients' signature: promise the above is true}

Date:

Figure 2 Primary screening questionnaire of patients and companions (3).

specialists from the infectious disease department, nursing department, hospital infection management department, and the discipline inspection commission office. The supervision group was divided into 4 teams, and the ophthalmology department was examined 3 times a week. The supervision items included diagnostic criteria for COVID-19, knowledge related to disinfection and isolation, the disposal of material from occupational exposure, usage and recording of protective equipment, sampling standards for suspected patients with COVID-19, treatment of suspected or confirmed cases of COVID-19, and medical waste disposal of material from suspected or confirmed cases of COVID-19. Improvements according to the supervision results were required to be completed within two days after the announcement on the Office Automation Platform. The inspection results during the early stages showed that some medical staff in the ophthalmology department were not familiar with the diagnostic standards, ward disinfection, and suspected case isolation. However, after several cycles of supervision-guided improvement, they became familiar with the prevention and control measures for COVID-19.

\section{Disinfection of the ward}

COVID-19 is transmitted mainly by droplets and contacts. As it was getting warmer in the south, we turned off the air conditioning. Ventilation was strengthened in the ward. The windows of the ward were opened for ventilation at least twice a day. In addition, the air in the consulting room was well ventilated and disinfected every 4 hours. After the patient was discharged from hospital, terminal disinfection was performed in the ward using an auto-disinfection 
Name:

ID:
Telephone:

Address:

1 Epidemiological history

(1) Whether you had Travel or residence history in high-risk areas of the epidemic within 14 days

$$
\text { Yes } \square \quad \text { No } \square
$$

(2) Whether you had contact with someone from high-risk areas of the epidemic or outside the country

$$
\text { Yes } \square \quad \text { No } \square
$$

(3) Cluster disease (2 or more cases of fever and/or respiratory symptoms in a small area such as family, office, school class, etc. within 2 weeks)

$$
\text { Yes } \square \quad \text { No } \square
$$

(4) Whether you had contact with the patient of COVID-19 or someone whose nucleic acid is positive

$$
\text { Yes } \square \quad \text { No } \square
$$

2 Clinical manifestation

(1) Fever and/or respiratory symptoms:

$$
\text { Yes } \square \quad \text { No } \square
$$

(2) It has imaging features of COVID-19:

$$
\text { Yes } \square \quad \text { No } \square
$$

(3) The total number of white blood cells was normal or decreased, Lymphocyte counts are normal or reduced:

$$
\text { Yes } \square \quad \text { No } \square
$$

\section{Patients' signature: promise the above is true}

\section{Date:}

Figure 3 Primary screening questionnaire of patients and companions.

machine (9). Reusable instruments such as slit lamps, front mirrors were disinfected with $75 \%$ ethanol once before and after use. Instruments including the tonometer head, front room angle mirror, 3 -sided mirror, various ophthalmic laser contact lenses and eye A ultra-probe which were in direct contact with patients' eye surfaces and tears were cleaned before use then wiped with $75 \%$ ethanol at least 3 times before each visit. The medical waste produced by the ward was cleared and transported, and the inner and outer surfaces of the garbage bins were sprayed with chlorinecontaining disinfectant containing $1,000 \mathrm{mg} / \mathrm{L}$ of available chlorine once every day (12).

The nurse manager of the ophthalmology department ensured the stock of hand sanitizers within their expiry date was sufficient, and encouraged medical staff, patients, and attendants to use these sanitizers (13). On March 27, after disinfection, air samplings and object surface samplings were carried out in the treatment rooms and 2 emergency isolation observation wards in the ophthalmic ward, we collected 21 specimens, and no pathogenic bacteria was found.

\section{Patient and escort management}

For the observation of patients with suspected COVID-19, the ophthalmology department of our hospital had two isolation wards, which were far away from the nurses station and were equipped with air circulation and separate toilets. Cases that met any one of the epidemiological history criteria in the questionnaire, or cases with no epidemiological history or met the clinical diagnosis of any two items, were required to be transferred to the emergency isolation ward to undergo an NCP nucleic acid test. The emergency plan of the ophthalmology department was then launched, as shown in Figure 4. The bed reservation system was implemented to ensure patients were hospitalized accurately and in order. In the early stages of the medical service recovery, the number 


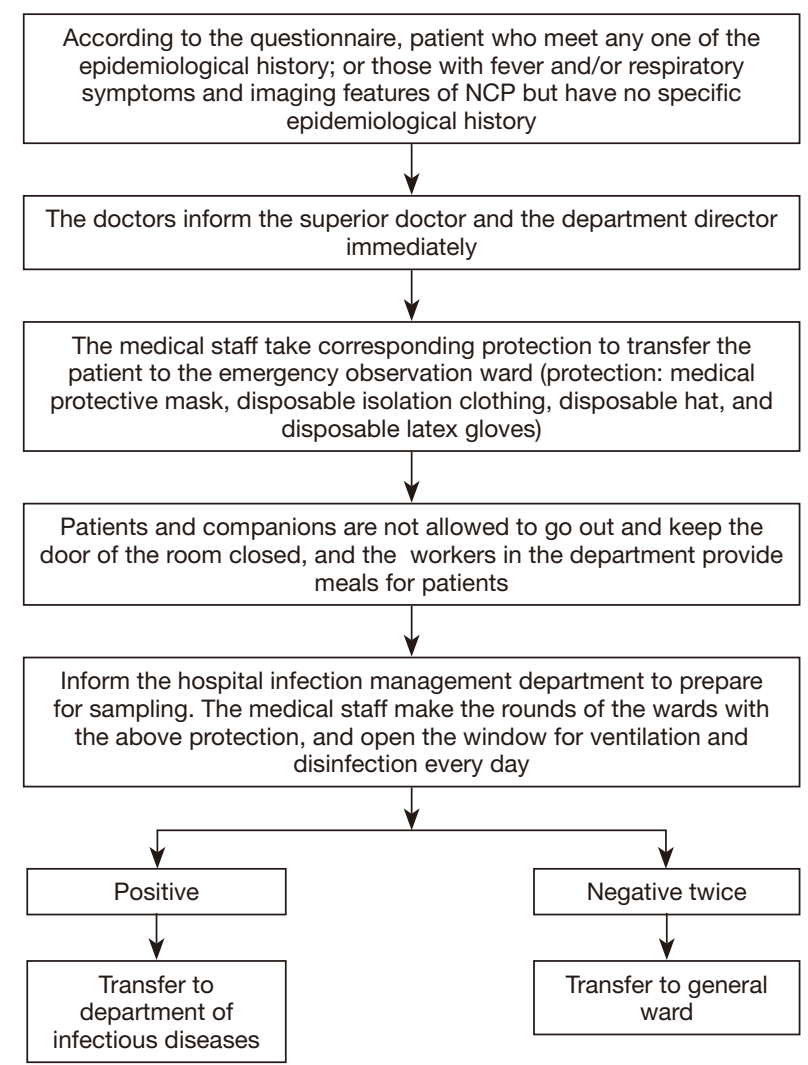

Figure 4 Emergency treatment procedure for patients with NCP in ophthalmology department. NCP, novel coronavirus pneumonia.

of patients increased steadily. It was suggested that the number of inpatients in the department should be controlled to account for $50-60 \%$ of the fixed beds. In regard to wards with more than 2 patients, whenever possible, an empty bed was placed between 2 patients to create distance. All patients were routinely screened with chest CT, and the procedure was performed after COVID-19 evaluation.

To minimize the gathering of people to avoid crossinfection, we also implemented strict management measures for escorts. One patient was only able to have 1 healthy escort who should not be replaced if he or she was ill or lasted for more than two weeks, and their temperature was monitored twice a day. If the attendant had a fever, the attendant was required to wear a surgical mask and was transferred to the fever clinic of our hospital by medical staff. Thus, the attendant was replaced by another one. The attendants were not allowed to gather in the aisle of the ward. Visits during hospitalization were not allowed, and the visitors could greet the patient via telephone or WeChat. If it was really necessary to visit a patient who was critically ill, the number of visitors was controlled, and visiting time was shortened during the epidemic. The primary nurses provided health education, including the prevention and control of NCP as well as cough etiquette. By April 12, a total of 37 people had been transferred to the emergency isolation ward of the ophthalmic ward, where 77 pharyngeal swab samples were collected, all of which were negative. In addition, 9 patient companions were detected to have fever in the ward, all of whom were taken to the fever clinic for treatment. Pharyngeal swabs were collected to detect the novel coronavirus, all of which were negative.

\section{Staff management}

The hospital established a compulsory health status reporting system. All staff had to wear masks at all times during working hours and carry out proper hand hygiene, and body temperature was measured and recorded 3 times a day. The health status of the staff was of great concern. Anyone who had fever or other discomfort will be reported to the dean of our department or the head nurse immediately. The physical and mental health of the staff was also considered. The psychosomatic department provided free psychological consultation services for all medical staff in the hospital, and provided lectures related to psychological guidance for all medical staff to relieve their working pressure and tension through office-software. A flexible scheduling structure of duty was formulated and implemented to ensure the enough rest of medical staff.

Ultimately the ophthalmic ward was infected with the novel Coronavirus without patients and medical staff. This shows that Ward settings, channel design, allocation of protective equipment, screening of hospitalized patients, supervision-guided improvement, ward disinfection, and the management of patient and escort were effective prevention and control strategies for the ophthalmology department in the process of recovering the medical service. Although the prevention and control of COVID-19 in our ophthalmology department was satisfactory, the tasks for medical institutions are still arduous. It is still necessary to implement strict control strategies and establish a set of practical emergency prevention and control guidelines in the ophthalmology department. We believe that we can achieve the ultimate victory of the COVID-19 pandemic in the near future. 


\section{Acknowledgments}

Funding: This work was supported by The Science \& Technology Department of Sichuan Province Academic Project (2020YFS0003); The Hospital Infection Branch of Sichuan Preventive Medicine Association Academic Project (HR19001) and The Affiliated Hospital of Southwest Medical University Academic Project (17224).

\section{Footnote}

Conflicts of Interest: All authors have completed the ICMJE uniform disclosure form (available at http://dx.doi. org/10.21037/apm-20-2424). The authors have no conflicts of interest to declare.

Ethical Statement: The authors are accountable for all aspects of the work in ensuring that questions related to the accuracy or integrity of any part of the work are appropriately investigated and resolved.

Open Access Statement: This is an Open Access article distributed in accordance with the Creative Commons Attribution-NonCommercial-NoDerivs 4.0 International License (CC BY-NC-ND 4.0), which permits the noncommercial replication and distribution of the article with the strict proviso that no changes or edits are made and the original work is properly cited (including links to both the formal publication through the relevant DOI and the license). See: https://creativecommons.org/licenses/by-nc-nd/4.0/.

\section{References}

1. Chen B, Zhang X, Sun XF. Precaution of 2019 novel coronavirus infection in ophthalmology medical staff. International Eye Science 2020;(3):1-6.

2. Jørstad ØK, Moe MC, Eriksen K, et al. Coronavirus disease 2019 (COVID-19) outbreak at the Department of Ophthalmology, Oslo University Hospital, Norway. Acta Ophthalmol 2020;98:e388-e389.

3. Romano MR, Montericcio A, Montalbano C, et al. Facing COVID-19 in Ophthalmology Department. Curr Eye Res 2020;45:653-8.

4. Zhang H, Qiao CY, Chen CZ, et al. Investigation and Study on ocular symptoms of ophthalmic medical staff diagnosed with COVID-19 in Wuhan. Ophthalmology 2020;29:18-24.

5. Mizumoto K, Kagaya K, Zarebski A, et al. Estimating the asymptomatic proportion of coronavirus disease 2019 (COVID-19) cases on board the Diamond Princess cruise ship, Yokohama, Japan, 2020. Euro Surveill 2020;25:2000180.

6. Interpretation of COVID-19 diagnosis and treatment protocol (trial version 6).Chinese Journal for Clinicians 2020;48:377-8.

7. General Office of the National Health

Commission,National Bureau of Disease Control and Prevention,State Health Office medical letter NO. [2020] 156 Notice of the General Office of the National Health Commission on the issuance of the CoVID-19 Prevention and control Programme (Fifth Edition) 2020-02-21.

8. Chu CY, Li CY, Zhang H, et al. Quarantine methods and prevention of secondary outbreak of pandemic (H1N1) 2009. Emerg Infect Dis 2010;16:1300-2.

9. Lam DSC, Wong RLM, Lai KHW, et al. COVID-19: Special Precautions in Ophthalmic Practice and FAQs on Personal Protection and Mask Selection. Asia Pac J Ophthalmol (Phila) 2020;9:67-77.

10. Hayashi J, Murata M, Furusyo N, et al. Measures taken by a university hospital for the prevention and control of the 2009 H1N1 influenza. Nihon Rinsho 2010;68:1707-12.

11. General Office of the National Health Commission, National Bureau of Disease Control and Prevention, State Health Office medical letter NO.(2020)75, Notice of the General Office of the National Health Commission on the issuance of guidelines (trial) on the scope of use of medical protective devices commonly used in novel Coronavirus pneumonia prevention and control 2020-01-26.

12. Killingley B, Greatorex J, Digard P, et al. The environmental deposition of influenza virus from patients infected with influenza A (H1N1) pdm09: Implications for infection prevention and control. J Infect Public Health 2016;9:278-88.

13. Updegraff JA, Emanuel AS, Gallagher KM, et al. Framing flu prevention--an experimental field test of signs promoting hand hygiene during the 2009-2010 H1N1 pandemic. Health Psychol 2011;30:295-9.

(English Language Editor: C. Betlazar-Maseh)

Cite this article as: Xia J, Wang R, Tian M, Wu X. How to restore medical services in the ophthalmic department in the post-pandemic period of COVID-19. Ann Palliat Med 2021;10(2):2331-2337. doi: 10.21037/apm-20-2424 